\title{
Mothers and babies in a Brazilian prison: a study exploring the impact of prison conditions
}

\begin{abstract}
In this article, we describe and qualitatively analyze the only prison in the state of São Paulo that houses mothers and babies. By law, Brazilian women inmates are only able to personally care for their babies until they are 6 months old. After such period, babies are placed with relatives or institutionalized. In this study, systematic observations and interviews were conducted with 8 prisoners over a period of 6 months. Results show that the child developmental process inside the prison can be aggravated by two main conditions: there was no possibility for the caretaker and the child to be involved in a series of important activities for child stimulation and the physical condition of the building was inappropriate, causing respiratory diseases in the children and subpar sleeping conditions for mothers and babies.
\end{abstract}

Keywords: prison, women, mother, baby, brazil
Volume 2 Issue 3 - 2016

\author{
Claudia Stella,' Vania C Sequeira,' Thais La \\ Rosa $^{2}$ \\ 'Mackenzie University, Brazil \\ ${ }^{2}$ Portland State University, Oregon
}

Correspondence: Claudia Stella, Universidade Presbiteriana Mackenzie, Rua da Consolacao, 896 Sao Paulo-SP-Brasil,Tel 55||-2||4-845|, Fax 55-||-2||4-845|,

Email claudia.stella@mackenzie.br

Received: February 14, 2016 | Published: March 16, 2016

\section{Introduction}

The guaranteed rights of children of women prison inmates is a complex issue that deserves attention, but can often be neglected in public policies in Brazil. Surveys about childcare in prisons, especially in Brazil, are still incipient and this is reflected in the lack of papers on the subject. Educational aspects of this type of care and its influences in the child's subjectivity have not yet been explored by public policies or in the academic field. In Brazil, when a mother is arrested there are three possibilities of support to her children (0 to 6 years old): a substitute family, that can be distant relatives of the child; shelter institutions; or prison nursery where children can stay with their mothers for some time, usually during breastfeeding period. This type of lodging is the object of the present study. In this article, we report research that aimed to describe and qualitatively analyze the only prison facility in the Brazilian state of São Paulo that houses mothers and their babies, and to critically evaluate aspects of this setting as a context for the children's development. This research is grounded in the belief that having a better understanding of the functioning of mother-child prison lodgings can offer solutions for the healthy development of children who experience this situation and help prevent the mother's criminal recidivism. It addresses a relevant scientific problem and a clearly defined social problem that concerns the execution of public policies aimed to guarantee the rights of children and mothers living in prison conditions.

Children of both men and women prisoners can face similar difficulties. However, in this paper we chose to study children of women prisoners because we understand that there are differences between maternal and paternal imprisonment, based on the fact that historically children have been women's responsibility and there is a higher probability that women prisoners are the sole carer of children. ${ }^{1}$ This is reflected on the data from the last São Paulo's ${ }^{2}$ Penitentiary Census, ${ }^{3}$ according to which only $20 \%$ of the children of women prisoners were under parental responsibility, while $87 \%$ of the children of men prisoners were take care by their mothers. At the time, most children of women prisoners were taken care by maternal grandmothers (40\%). This demonstrates that usually responsibility for the child lies with the mother's family when she is absent. Literature ${ }^{3,4}$ describes that child custody experiences in prison are developed during the breastfeeding period. Several institutions sustain that children should be kept with their mothers for the first months, seeing that this is healthy for the mother-child relationship; it reinforces bonds and contributes for the prisoner's ulterior social reinsertion. ${ }^{5}$

Brazilian Constitution ${ }^{6}$ states that the education of children is a right and the provision of education is a duty of the State. This stipulation is reiterated by the Statute of Children and Adolescents ${ }^{7}$ - which is partly based upon the United Nations Convention on the Rights of the Child (1989) - and combines measures for the protection and education of children. In addition, the Brazilian Ministry of Justice $^{8}$ issued the following statement: "children of incarcerated people, age range 0-6 years old will have guaranteed access to preschool education". The Brazilian Penalty Execution Law is similarly clear in recognizing that very young children should be with their mother: "Prison institutions dedicated to women must have a nursery where inmates can breastfeed their children". ${ }^{9}$ However, a national survey of incarcerated women by the Ministry of Justice ${ }^{10}$ showed that only $19.6 \%$ of women's penal institutions in Brazil had nurseries for babies or an equivalent facility, and only $16 \%$ had a daycare for children under 6 years of age. In $51.6 \%$ of Brazilian prison institutions, childcare was improvised; children stayed with their mothers inside the cell. In an earlier study, Santa Rita ${ }^{11}$ identified ten facilities in correctional institutions for women, which collectively housed 69 children. Despite the lack of daycare infrastructure, some prisons did shelter newborns and very young children on an impromptu basis during the breastfeeding period.

While there are difficulties in Brazil with accessing official national data on women inmates, two recent reports suggest a profile of incarcerated women that is likely to need facilities for children. Braunstein's ${ }^{12}$ study of a female penitentiary in São Paulo showed that $79 \%$ of the women were mothers and $50 \%$ had children younger than 12. The female prisoner population was also very young: $57 \%$ were 
between 19 and 29 years old. A similar profile of women prisoners was evident in a government report that described the typical inmate as: (...) young, single, mother, African-descent, and in most cases, convicted for drug dealing. She presents such a strong bond with the family that she would rather stay in a public, insalubrious, overcrowded, and uninhabitable prison; with the chance of receiving family and children visits, than to go to a distant penitentiary, where she could eventually have access to remission of penalty for work or study, professional training as well as better inhabiting conditions. ${ }^{13}$

While these reports show that some data on Brazilian incarcerated women is available, their children are an almost completely ignored segment of the population. This can be seen in the scarcity of Brazilian literature on the subject of children in prisons, the absence of public policies, the poor training of professionals and lack of social institutions to receive and deal with this population. For example, data from a Brazilian Ministry of Justice ${ }^{10}$ survey showed that while $56 \%$ of women's penitentiaries had psychologists on staff in the prisons that did allow nursing babies, only $11.7 \%$ had pediatricians. Although Brazilian legislation recognizes the needs of maternity in a prison context, there are gaps concerning service provision for small children in prisons and little acknowledgement about the implications of imprisonment for parents and children. For Adl et al., ${ }^{14}$ children that undergo the experience of having their mothers incarcerated are at higher risks in several aspects and usually endure living conditions marked by poverty and instability.

The issues related to keeping children in prisons are complex, due to both the punishing purpose of the prison environment and the aggressive potential of the adult relations established inside it. There is clearly a tension between the needs of the baby and the prison's institutional regulations. Sarradet, ${ }^{15}$ who studied children living in prisons in France, asserted that in their daily lives, children in prison are introduced to a world of surveillance, full of cells and guards, and become as imprisoned as their mothers. In different countries considerable discrepancies can be found in the period that children are allowed to remain with their mothers. It usually varies from 18 months to 6 or 7 years old, but most countries allow them to stay with their mothers up to 3 years old. As there is no international standard for children who live with their mothers in prison, varying practices in relation to maternal incarceration can be found around the world. In China, for instance, law determines that pregnant women should not start serving their sentence before the child is 12 years old, and children are not allowed in prisons. In Uganda and Hong Kong children can stay with their mothers in prison up to 3 years. ${ }^{14}$ Since parental contact is fundamental for children, Italy's constitution also guarantees 3 years of mother-child contact within prison. ${ }^{16}$

The small numbers of national and international studies on the topic of babies in prison and the lack of systematic data in several countries have contributed to the use of the term "institutional invisibility" to denote ignorance about children of prisoners. ${ }^{17}$ In the present research, we consider the prison environment as a specific context for human development, following Bronfenbrenner's ${ }^{18}$ model of integral development and the impact of the environment on psychological growth. His ecological theory of human development provides a way of understanding the developmental processes that happen within the immediate environment of human relations, and which are deeply affected by conditions and events of the overall context in which they are situated. We argue, however that prison cannot be taken as a neutral environment or equivalent to a home or school setting. To further understand prison as a socially punitive institution that can influence the ecological context of people who live inside it, we turn to the theoretical constructs of Foucault ${ }^{19}$ and Goffman. ${ }^{20}$ Foucault ${ }^{19}$ taught us that prison does not give back to society "corrected" individuals; but rather it creates a delinquent population that often returns to prison. "Prison also produces delinquents by imposing violent constraints on its inmates; it is supposed to apply the law, and to teach respect for it; but all of its functioning operates in the form of an abuse of power".

By placing the individual into a confined world of crime, prison deprives inmates of their family and possible means of a livelihood and forces prisoners to live a violent institutional routine. For Goffman, ${ }^{20}$ prison is a total institution; its routine - not only daily life, but also the relations between inmates and the staff - is formally administered, with regulated and imposed rules. Many domination processes happen through institutional practices of "abasements, degradations, humiliations and profanations of the self". Goffman ${ }^{21}$ considered total institutions as a serious threat to the self. In particularly, prison subjects are deprived of their identities and individuality and compose a mass of equals. The process, called "mutilation of the self", is intensified by the personal mis-configuration imposed by the institution. For example, the standardization process in physical appearance can particularly affect women inmates, since cultural practices of the outside world prioritize female individualization in clothing and appearance. Prison constructs within inmates (and even former inmates) a situation whereby there is an inability for complete social acceptation.

Goffman $^{22}$ stated that such stigma goes beyond the stigmatized individual. To Goffman, when one individual has a link or relationship with a stigmatized person (such as an inmate or someone with a disease or handicap) through a social structure (such as affiliation), these relationships can lead wider society to treat both individuals, in some respects, with the same stigmatization. Thus, the baby of a women prisoner is also seen as a prisoner. From a psychoanalytical point of view, it is also likely that the mother-child relationship is influenced by the violence of the punitive system, due to the mutilation of the self that the mother goes through in prison and the distinctive character of the stigma. Recent research has demonstrated that the punitive nature of prison may influence the development of the relationship between mothers and their children. The prison environment presents certain specificities that bring to light its punitive character, but also all the social meaning of prison, which is often represented in the staff voices about children in prison: the children are not guilty, but can be used by their mothers to receive better treatment in prison. ${ }^{17}$

Other studies note that the inclusion of babies in prison not only strengthens bonds and is healthy for mother-child relationships, but that it also contributes to the further social reinsertion of the inmate. ${ }^{3}$ Motherhood and mother-child bond is also influenced by the emotional well being of inmates, their relationship with family and their preoccupation with an uncertain future. Recidivism decrease of mothers in prison has been explained by Farrall ${ }^{23}$ who points out that the causes of criminality might be linked with family or community abuse and that the change of family roles, such as to become "a good mother" or "a good father", can discourage people from engaging in criminality. Parenting programs can include a revision of the inmate's own parenting and contact with their families. Prisoners also learn more about child development and how to relate to their own children in an age-appropriate way. ${ }^{24}$ 


\section{Prison environment as a specific context for human development: bronfenbrenner's theoretical framework}

According to Bronfenbrenner, the process of development happens in the immediate environments of human relationships and is deeply affected by conditions and events of the wider environment. Bronfenbrenner highlighted three components of this concept: the person's conception as being active; the reciprocity (or interaction) between person and environment; and the wider concept of environment. ${ }^{18}$ For Bronfenbrenner, at the most internal level of the ecologic environment is the micro system, which comprises the developing person and their primary relations. On this level, in which face-to-face interaction is experienced, the individual experiences activities, roles and interpersonal relations in an environment with specific traits and qualities. In the microsystem, "to experience" is the key word, since the environment does not consist solely of its objective characteristics, but of the perception that the individual has of that environment. At this level, connections among other people who are present in the environment, and the nature of these bonds, have an indirect influence over the developing person, through the effect they have on face-to-face interaction.

In the micro system, the dyad (a two-person system) is an important relationship to analyze. The dyad constitutes an important aspect for development, serving as a base for other forms of relationships, such as triads and tetrads. The reciprocity component, in the established relations, provides concrete hints for the understanding of developmental changes not only in children, but also in adults, their primary caretakers: mothers, surrogate mothers, fathers, grandparents and institution workers. Dyads described by Bronfenbrenner ${ }^{18}$ can be of three types:

\section{i. observational dyad, \\ ii. joint activity dyad and \\ iii. Primary dyad.}

The observational dyad occurs when a member pays attention to the activity of the other, who in turn, notices and acknowledges this attention, providing explanation and occasional commentary on their activity to the observer. Joint activity dyad is established when members perceive themselves doing something together, not necessarily the same thing, but developing different functions in the same activity. Primary dyad is the two-way system that exists for both participants, even when they are not close, such as the motherchild. The primary dyad has a strong emotional component and can be combined with an observational dyad or have joint activity. For Bronfenbrenner, ${ }^{18}$ it is more likely that the children acquire values, knowledge and abilities from a person with whom they established a primary dyad, than with a person that has no emotional significance for them.

Bronfenbrenner ${ }^{18}$ also argued that for the proper functioning of the primary dyad, it is necessary for a third person to be involved, such as the father in the mother-child dyad. If this third person is lacking or plays a disturbing role, the developmental system is broken. Inside the prison system, the primary dyad can be compromised because a third person (who might normally have a bond with the mother and child - such as the father), is not present or this primary dyad can be influenced or interrupted by the daily prison system rules and regulations. Bronfenbrenner's conceptions about the dyad and human development were used in the process of our research, including the design of the observation protocol, the interviews and the analysis of the results.

\section{Methods}

\section{Procedures}

Qualitative research methods were used to conduct an exploratory case study of babies in prison. Systematic observations and interviews were conducted in a mother-child facility inside a female penitentiary in São Paulo, Brazil, during weekly 5-hour sessions over a period of 6 months, totaling approximately 120 hours. The interviews were done in the dorm rooms, during the ongoing series of observations, spontaneously, in accordance with the desire and availability of the interviewees and without the presence of guards. When issues arose during the observations, the interviews were used to elucidate these issues. The interviews were not recorded, since recorders were not allowed inside this prison. Researcher annotations and a field journal were also part of the data. The observations and interviews were used to build the subsequent sections, and it was through the speech of mothers and employees that we could understand the functioning of their environments and interactions inside the prison. The research was submitted and approved by two research ethics committees: one from the university and the second from the Office of Penitentiary Administration of the State of São Paulo. The research followed all ethical principles and is based upon human rights precepts and on theories by Bronfenbrenner, Goffman and Foucault.

\section{The environment}

The São Paulo prison facility featured a courtyard for exercise and to receive visitors. There was a playground reserved for older children that came to visit their mothers, but it was not appropriate for the very young children who were living inside the prison. Some of the mothers reported that their other children used this space when visiting them. The building had three floors: on the first floor there was administration, a refectory and a kitchen. On the second floor, there was a nursery to assist mothers and babies, a recreation room and dormitories (dorm rooms were shared between 2 women and their babies). To reach the second floor, one must climb the stairs and pass an iron gate and guards. It is noteworthy that the dorm rooms had no cradles and babies slept in the same bed as their mothers, putting babies in danger of being accidently rolled over or smoothed, which kept the mothers on alert: "I do not sleep well, I'm too scared I will roll on him and suffocate the baby". The third floor was similar to the second, but there were vacant rooms; one of the rooms was used for smoking.

It was possible to observe that the institution did not provide a space for child stimulation, and there were no toys and all of the walls had the same white colors (except for some dorm room walls, which displayed pictures taken from magazines or drawings made by the mothers).

\section{Participants}

There were 61 incarcerated women and their children (same number), with 5 of the children hospitalized. The women were young (19- 31 years old) and the majority of them had been arrested for drug trafficking or robbery. Babies were allowed to stay at the institution up to 180 days (6 months) after birth; however, children older than 9 months were found living there. All 61 of the mothers in the prison were invited for the interviews, but only 8 prisoners agreed to talk with 
us. One possible explanation for this low number could be criminal gangs, which are a powerful influence inside Brazilian prisons and have a mistrust of any perceived cooperation outside of the gang units, and perhaps are concerned that any collected information could be used against them. This places a mark of fear in the inmates. The participants signed an informed consent and the project was approved by Platform Brasil, a federal electronic system to which every research involving human participation must be submitted. Regarding the prison routine, mothers woke up at approximately 9:30 am and had lunch at $12 \mathrm{pm}$. At $3 \mathrm{pm}$ they had a coffee break; dinner was at $6 \mathrm{pm}$. All the mothers were always together, under vigilance, without possibility for individuals needs.

The prison staff was composed of: 18 guards working in shifts (12 hours work, 36 hours rest) with the right to 3 consecutive days off per month; support staff consisted of 1 social worker; 1 pediatrician; 1 gynecologist, 1 psychologist; 1 nutritionist; and 3 administration employees. The support staff did not spend every day with the women and their children, and usually the staff visited the unit once per week. We decided that the employees interviewed would be the guards and of the 3 guards invited to participate, each showed some interest in our research and some sensitivity regarding the situation of mothers living with their babies in prison. During our observations, we overheard several instances of loose talk from the staff that reflected the prejudicial social position: that crime can be passed from mother to child. This attitude could be an influence on the little stimulation that babies receive while inside the prison, both from the state and the prison's employees.

\section{Analysis approach}

The research based its approach using ethnographic studies of anthropology, whereas researchers observe (and describe in detail) human behavior in specific environments in order to produce scientific knowledge. ${ }^{25}$ The observation and interview records were read, systematized and analyzed by the Thematic Analysis. To Guest et al., ${ }^{26}$ the Applied Thematic Analysis (ATA) has been used to describe and to perceive how, in a specific context, people feel, live and think about a research question, within a rigorous method. In the authors words: "To summarize, the ATA approach is a rigorous, yet inductive, set of procedures designed to identify and examine themes from textual data in a way that is transparent and credible" (p.15). As the ATA described, we tried to give voice to the participants. The data records collected were read to identify possible themes and three researchers were individually responsible for manually coding the data and finding direction to provide meaning.

Weekly meetings were organized during the data collection process, so each researcher could present and discuss his or her themes. The themes chosen were the common ones to the three researchers. When a theme was only observed by one of the researchers, the other two were instructed to explore the theme in the following interviews to confirm its existence or its absence. The Thematic Analysis was adapted to categorize the reflections in the observations, organizations, and interviews' analysis, especially critically evaluating developmental aspects inside the prison units. Results of the research were presented in themes. The dyads that Bronfenbrenner described were used as a framework for conducting our research and for the analysis of the prison environment.

\section{Results and discussion}

A prison is a highly complex, tightly controlled environment. Exposing children to their prisoner mother implies in depriving them of social freedom and constrains them to a restrict residence; on the other hand, taking them away from their mother implies in separating them from the affective care necessary to human development.

Observational studies offer the possibility to describe and observe the environment, revealing details about the interaction between person-environment. Observations and interviews were made during the prison visits in order to get acquainted with the routine of the imprisoned mothers and their babies (age range 0-6 months old). Given the unique aspects of prisons, in regards to the daily workings of this complex environment, we were able to study the mother-infant interaction and the developmental possibilities of the children. As a result of the data analysis, our results were organized under two major themes. The first theme was named prison and baby development. The second theme was named mothers in prison.

\section{Prison and baby development}

Regarding the effects of life in prison on a child's development, these were the themes that emerged in the data analysis: child's stimulation and lack of psychological support, food quality and breastfeeding, and lack of temperature control. Child's Stimulation and Lack of psychological support: Mothers were solely responsible for stimulating their children. Mothers reported doubts about their babies' normal development and were concerned as to whether or not they were giving their babies adequate stimulation. Many mothers, knowing that we were psychologists, questioned whether they were stimulating their babies correctly or if their development was normal: "Do you think she is appropriately developing for her age?", "What can I do to make him smarter?". This indicates that some prisoners were denouncing the lack of institutional support to deal with babies.

While mothers were responsible for their babies' daily care, such as bathing and feeding, child stimulation was also their responsibility. The institution did not provide a proper place for any type of play area and/or pedagogic activity for babies; nor did the prison have experts in child development on staff. In one of our visits, we observed a mother stimulating her son to crawl, putting him on the floor and placing a cup at a certain distance so that the baby would make an effort to reach it. Another mother reported that she used to sing to her baby because she believed she could calm him down and help him develop speech. Thus, in the absence of external stimulation mothers did their best and normal mothering activities occurred despite the lack of facilities.

\section{Food quality and breastfeeding}

Inside the prison, mothers fed their babies with milk, either breast milk or industrialized formula. Mothers complained heavily about the fact that there was not enough industrialized formula milk, which was provided by the State. Concerning nourishment, one of the most important complaints was about food quality - for instance fruit was often not ripe - and the absence of proper food for babies. ${ }^{27}$ On the other hand, the staff expressed a view that the mothers were there to breastfeed their babies, and if they, for one reason or another, could not do it, they should not be in that particular unit. For example, one employee said: "This is a unit of breastfeeding, those who do 
not breastfeed should return to a regular prison unit and the babies should be delivered to their families. They (the prisoners) often take advantage of this situation." It is important to note that breastfeeding within this particular prison is looked at from a medical standpoint. ${ }^{28}$ Thus, the staff did not seem to see breastfeeding as an important socio-emotional moment for mothers and babies, but as a medical requirement for mothers who joined this program. The Brazilian public policy that addresses mothers with babies inside prisons places so much emphasis on a single medical issue-breastfeeding, that it largely ignores the holistic development of the relationship between mothers and babies, which is so important during this period of life.

\section{Lack of temperature control}

Our observations also showed that due to temperature fluctuations within the prison, mothers gave inhalation therapy to their babies treatments designed to improve or restore breathing. During the visits we obtained this information from staff and inmates, and were told that inhalation therapy was performed due to the high number of children with coughs. This therapy was recommended by the prison pediatrician - three times a day for ten days - with equipment being provided to inmates by the government. Structural problems within Brazilian prisons -such as the issue of fluctuating temperatures- were the subject of constant staff complaints. Several prisons become too cold in the winter and too hot in the summer, which brings health problems for adults and, of course, causes major damage to babies, whose health is more susceptible. A mother expressed a belief that the cause of respiratory illness of her baby was from the cold temperatures inside the prison during the winter. ${ }^{29}$ "My baby got sicker when the temperature dropped last week because it's so cold inside my cell and I don't have any way to keep her warm."

The lack of proper child stimulation, malnutrition and precarious institutionalized living situation can lead to delayed general and cognitive development. The addition of colored walls, drawings and objects for babies' stimulation, as well as toys, cribs and adequate food and temperature control inside the prisons would improve children's developmental conditions without harming the restriction of liberty or security of the female penitentiary. Prisons could foster child development by incorporating nurseries and schools in its premises.

In general, our observations showed that all mothers seemed to take care of their children's basic needs and were happy to spend ample time with them. The overall quality of the childcare mothers provided was positive, and no kind of mistreatment or negligence was observed.

\section{Mothers in prison}

\section{Parenting compulsory course}

The mothers' main occupation was to take care of their children, but they were also expected to attend a compulsory course that coincided with the research period, which dealt with themes such as: maternity, women's rights, feeding, etc. The content was similar to international parenting programs that teach "how to be a good mother". However, the requirement of compulsory attendance aroused mixed feelings in mothers, depending on the number of children they already had. Mothers with their first babies said the course was good and they were learning a lot, but mothers with other children had a different opinion: "After three kids, I know very well how to take care of a baby, I do not need this type of course, I can use my time for something else."

\section{Criminal recidivism}

Another theme uncovered in the mothers' speech was related to criminal ecidivism. For example, one mother said: "Now, I have my baby and life is different, right? I need to get out, get a job and be careful with bad influences, I do not want to return inside prison and leave him alone. I want to be a good mother". Being a good mother, socially, can mean not offending or re-offending, so being in prison challenges this stereotype because the State assumes responsibility for the mother and for her motherhood. ${ }^{30}$ Once the institution denied the prisoners the freedom of individual expression of identity, ${ }^{20}$ the mothers were filled with self-doubt about their ability to take care of a baby.

\section{Religious services}

Another regular activity attended by mothers was various religious services that took place on Saturdays. Attendance was not compulsory, but it was an important activity for many women. It provided a support system and encouragement for the mothers to keep going despite the sentence of imprisonment and it also encouraged them to take good care of their babies. A mother of a young baby said: "If it were not for God and the brethren of the church that comes to visit, I would not have the strength to face the life here together with my baby, I ask God for courage when my baby has to go". Mothers and babies were influenced by the threat of punishment within the prison environment, which included the possibility of restricting their interaction, inside this highly administered context. Therefore, to understand the custody of children, it is important to understand the functioning of Microsystems and dyads, considering that although activities are restricted to the immediate environment, it can assume a "higher order of complexity"18 through other relations.

All three types of dyads described by Bronfenbrenner were observed. Examples of observational dyad included several instances where the mothers allowed their babies to be placed together on the floor and the mothers watched and talked about the babies' development. ${ }^{31}$ The second dyad, joint activity included several moments of mothers staying with their babies and singing and playing and storytelling to the child. In the study, the strength of the primary dyadic bond was noteworthy and it is highly emotionally charged. Even for mothers without their babies - due to hospitalization or in the process of separation - this emotional component was present and could be observed in depressive behaviors and in the mothers' words: "I do not even want to think when he leaves here, I think a part of me will not survive". There is the fact that the dyad has a closing date (the child is allowed to stay in the prison as long as six months), and this can influence the affective investment between mothers and babies: "I know she will go out, prison is no place for any child, I know I will suffer, I'm getting ready, but it's the best for her".

It is important to note that only the children that will be placed with relatives go through a process to ease the mother-child separation. A few months before the separation, these children start to spend weekends with relatives. ${ }^{32}$ The children that will be institutionalized go through the separation process without any preparation. Additionally, fruit is added to the every child's diet after their fourth month of life in order to prepare them to wean off breastfeeding. We also observed that the punishing character of prison is an environmental interconnection that affects the functioning of the dyad, since the third person can be represented by the prison institution itself. The mothers were strongly linked with their babies and because they were their main caregivers, 
watched them in all activities, and even during interviews never stopped watching and caring for the babies. But the punitive character of the prison and its dangerousness affect this activity as exemplified in this mother's statement: "This is prison, nobody is nobody's friend, I'm afraid that in a situation of disagreement the babies could be threatened." Based on Bronfenbrenner concepts, in an environment as highly guarded and as aseptic as the prison unit studied, we noticed the impossibility of experiencing important developmental aspects, like the understanding of the environment's wider concept, needed for the establishment of reciprocity which undertakes the development of a person's conception.

In our study, we observed that prison babies do not have what would be considered 'normal' stimulation of a typical child their age, including access to a variety of food, family support, toys, a temperature controlled environment, etc. In addition, many mothers were so stressed about being imprisoned with their children, that they felt insecure to provide psychological support to their child. "I am so worried about what being raised inside a prison is doing to my baby and how it will affect him."? The child developmental process inside the prison can have its effects aggravated by two conditions which were observed in the institution: there was no possibility for the caretaker and the child to be involved in a series of important activities for child stimulation and the physical environment was inappropriate, as exemplified by the precarious health of babies and the lack of appropriate sleeping accommodation for mother and child. Additionally, the fact that the mother was emotionally involved with the punishment - in the sense of the mortification of the self, described by Goffman ${ }^{20}$ - and with the inevitable separation from the baby, it may deprive the child of a stronger emotional connection.

\section{Final considerations}

In Brazil, for the child (0 to 6 years old) of an incarcerated mother, there are three possible options of guardianship: care by family members or surrogate families, children's shelters, or the penitentiary's daycare or nursery. At the end of this study, we conclude that inside prison is not the best place for a baby's development and the public policies in Brazil still have a long way to go. The prison units that shelter mothers and their babies should follow the norms of childhood development, looking towards solving both the needs of the baby and the mother, while maintaining the security aspects, ensuring that children's rights are a priority, creating conditions to improve mother-infant relationships and providing a stimulating environment for babies, which is so important in early childhood development. This developmental aspect could be performed in external shelters for mothers and babies during the breastfeeding stage, allowing mothers to care for their children without the pressure of a punitive environment and the State to protect the best interest of the child. ${ }^{33}$ Respiratory diseases may be a consequence of building construction or architecture, although it could also be the result of the emotional and stressful situation experienced by mothers and babies. The building and architectural issues deserve its own separate research study and evaluation. Research literature shows us that even if faced with traumatic mother-child separation following the first half-year of life, babies can overcome and adapt to their situation better and faster if they have the chance to develop and experience a meaningful emotional bond with the mother or other caretaker before separation. But it also stresses that environmental adjustment is necessary for this bond to be established.
Therefore it is essential to guarantee the children's right of access to their mothers, regardless if they are under custodial sentence, and this access should happen under appropriate conditions and location. Child stimulation should occur preferably in the dyad. Considering the questions raised by Goffman and Foucault, mothers have no conditions to stimulate their babies, since they are not stimulated themselves and this may aggravate the state of developmental delay of the baby. Therefore, the reduction of the hostility and violence in prison environments is essential. The State sentence is freedom restriction, not humiliation and violence, as indicated by Goffman and Foucault. So, we can agree that it is possible to improve the environment in regard to mother-baby care, without harming the unit's security system. Notable also, is the lack of training of the staff dealing with mothers and babies inside prisons. This situation requires, from the government, a significant educational investment in professionals towards a change in attitude and concerted effort to fight against social prejudice. Staff with expertise in child development in nursing, and in care of mothers and babies, could bring important and quality interventions in mother-baby relationships, as well as education and orientation for babies' stimulation. This would greatly improve these special units, both in the realms of education and public health.

At the end of this work we concluded that the prison environment; due to its violence, punishment and social isolation, can negatively influence the development of children living within it. The motherbaby dyad can be established (or affected) by several factors, such as: the meaning that the prison has for mothers, the insertion in a highly administered environment, the inter-relations amongst the mother and penitentiary agents, other inmates, visitors or the institution itself. In this type of environment, the child can experience difficulties in being introduced to other levels of social interaction. This reflects the objective of the prison institution, which is punishment and not childcare and education. Although this study focuses on the reality of 8 female inmates in Brazil, we believe that the data collected by the survey and its conclusions, may be of use to several professionals and researchers working with women, motherhood, inmate populations and child development. ${ }^{34}$ Besides psychologists, other professionals such as social workers, children specialists and law makers can also be benefited by the findings of this research since they can pressure society and the government to discuss the implementation of alternative programs to pregnant offenders.

The challenges that must be faced are: the development of proposals and strategies to address incarcerated women and their babies; the staff and professional administrators could minimize or reduce the potentially perverse impacts of maternal prison for child development; and the guaranteed access to maternal care in adequate conditions with a stimulating environment. According to the United Nations Convention on the Rights of the Child, ${ }^{35}$ every child has the right to day care and educational spaces, including the children of incarcerated women. These mothers were sentenced by the State and are being held legally accountable for their acts. The State, on its turn, should respond legally to the rights of the child, by not punishing any child for the mother's action, by not depriving maternity and causing significant social damage.

\section{Acknowledgments}

None. 


\section{Conflicts of interest}

The author declares that there are no conflicts of interest.

\section{References}

1. Rachel T, Rachel B. Women in Prison and Children of Imprisoned Mothers. Quaker United Nations Office, Geneva, Switzerland. 2004.

2. São Paulo. Estatísticas. 2002.

3. Fundap. Censo penitenciário 2002. São Paulo. 2009.

4. Farrell A. The experience of young children and their incarcerated mothers: a call for humanly responsive policy. International Journal of Early Childhood. 1994;26:6-12.

5. Stella C. The implications of mother's imprisonment in the life of their children. Journal of Criminal Science. 2001;34:237-264.

6. Mello DC, Gauer G. Maternity Housing in a Women's Prison in the State of Rio Grande do Sul. Saúde \& Transformação Social / Health \& Social Change. Sin mes. 2011;113-121.

7. Brasil. Constitution of the Federative Republic of Brazil. Legislative Activity. 1988.

8. Brasil Congresso Nacional. Lei no 8.069: Statute of Child and Adolescent. 1990.

9. Brasil Ministério da Justiça. Rules for treatment of prisoners in Brazil. 1995.

10. Brasil Congresso Nacional. Lei $n^{0}$ 7.210: Execução Penal, Penalty Execution Law. 1984.

11. Brasil Ministério da Justiça. Incarcerated women: national diagnose. 2008.

12. Santa Rita RP. Creche no Sistema Penitenciário: study on the situation of the first infância nas units of Brazilian female prison units. MonographEscola de Governo do Distrito Federal, Brasília. 2002.

13. Braunstein HR. Imprisoned Mulher: costume between indignação e or sofrimento by atos de humilhação e violência. Master's Degree Thesis in Education-São Paulo University, Brazil. 2007.

14. CEJIL. Report on imprisoned mulheres not Brazil. 2007.

15. Adl F, Dadkhah A, Biglarian A. Physical and social circumstances of children in Iran affected by the incarceration of the mother. International Journal of Social Welfare. 2007;16(3):278-280.

16. Sarradet JL. L'enfant de 18 mois vivant in détention avec sas mère. In: Michaud M, editors. Infants, parents, prison. France: Fondation de France. 1992.

17. Ferrara P, Emmanuele V, Nicoletti A, et al. Mothers with their babies in prison: the first Italian experience. Archives of Disease in Childhood. 2007;92(2):183.
18. Pösö T, Enroos R, Vierula T. Children residing in prison with their parents: an example of institutional invisibility. The Prison Journal. 2010;90(4):516-533.

19. Brofenbrenner U. A ecology of human development: natural and planned experiments. Alegre: Medical Arts, Brazil. 1996.

20. Foucault M. Watch and punish: nascimento da prisão. Petrópolis: Vozes. 1997.

21. Goffman E. Asylums: Essays on the Social Situation of Mental Patients and Other Inmates, Tradução: Dante Moreira Leite. São Paulo: Perspectiva, Poland. 1996.

22. Goffman E. Estigma, Stigma. Rio de Janeiro: Guanabara Koogan. 1988.

23. Farrall S. Social Capital and Offender Reintegration: Making Probation Desistance Focused. In: Shadd M, Russ I, editors. After Crime and Punishment: Pathways to Offender Reintegration. Devon, UK and Portland Oregon: Willan Publishing. 2004.

24. Mills A, Codd H. Prisoners' Families and offender management: mobilizing social capital. Probation Journal. 2008;55(1):9-24.

25. Geertz C. The interpretation of cultures: selected essays. New York: Basic Books, USA. 1973.

26. Guest G, MacQueen KM, Namey EE. Applied thematic analysis. Thousand Oaks, California: Sage. 2012.

27. Dallaire DH, Zeman JL, Thrash TM. Children's experiences of maternal incarceration-specific risks: predictions to psychological maladaptation. J Clin Child Adolesc Psychol. 2015;44(1):109-122.

28. Kauffman K. Mothers in prison. Corrections Today. 2001;63(1):62-65.

29. Harms T, Cryer D, Clifford R. Infant and toddler environment rating scale revised Edition (ITERS-R). New York: Teachers College Press, USA. 2003.

30. Spitz R O primeiro ano de vida. The first year of life: a psychoanalytic study of normal and deviant development of object relations. São Paulo: Martins Fontes. 1993.

31. Morago JMJ. The quality of educational attention received by children living with their mothers in Spanish prisons. Psychology in Spain. 2005;9(1):13-20.

32. Dillner L. Keeping babies in prison. BMJ. 1992;304(6832):932-933.

33. Stella C. Films of mulheres prey. Solutions and impasses for your development. São Paulo: LCTE Editora. 2006.

34. Craig SC. A Historical Review of Mother and Child Programs for Incarcerated Woman. Sage Journal. 2009;89(Suppl 1):35S-53S.

35. United Nations. Convention on the Rights of the Child. Adopted and opened for signature, ratification and accession by General Assembly resolution 44/25. 1989. 